\title{
Letrônica
}

\section{As causativas na língua japonesa}

\section{Causatives in Japanese language}

Rachel Antonio Soares

Doutoranda em Linguística pela Universidade Federal do Rio de Janeiro e graduada em Letras Português-Japonês.

rakkeru@gmail.com
RESUMO: Este trabalho tem como objetivo primeiramente elaborar uma síntese sobre os tipos de causativas nas línguas naturais para posteriormente abordar os três tipos de construções causativas na língua japonesa, a saber, as causativas lexicais (improdutivas), as causativas sintáticas (produtivas) e as causativas-zero, e focar em seus fenômenos idiomáticos visando uma maior contribuição para o estudo de questões gramaticais dessa língua.

PALAVRAS-CHAVE: operações de ajuste de valência; causatividade; língua japonesa.

ABSTRACT: Firstly, the aim of this paper is to provide a critical overview of the studies concerning types of causatives in natural languages and to approach three types of causatives in Japanese language, namely, lexical causatives (improductives), syntactic causatives (productives), zero-driven causatives, and focus on its idiomatic phenomena seeking a greater contribution to the study of the grammatical structures of this language.

KEYWORDS: valence adjusting operations; causativity; Japanese language. 


\section{Notas preliminares}

$\mathrm{P}$

ara a transcrição de termos em japonês, utiliza-se como padrão o sistema Hepburn $^{1}$, criado por James Curtis Hepburn (1815-1911). O referido sistema consiste na transcrição romanizada dos sons da língua japonesa, ainda que a bibliografia consultada não utilize tal padrão de transcrição. A tradução (livre) das citações e dos termos relacionados a esses materiais se encontra nas notas de rodapé. As abreviações e as convenções utilizadas ao longo deste trabalho, podem ser encontradas após as referências bibliográficas, no Anexo I.

\section{Introdução}

O que é causatividade? 0 que se entende por tal tipo de operação? 0 embasamento teórico mais satisfatório que encontrei inicialmente para compreender teoricamente a estrutura da língua japonesa foi em Payne (1997), um estudo que passarei a citar com certa frequência.

Para compreendermos tal fato linguístico primeiramente é necessário saber o que são operações de ajuste de valência (valence adjusting operations e, consequentemente, o que é valência. O termo pode englobar noções semânticas, sintáticas e semântico-sintáticas. As noções semânticas envolvem o número de participantes que têm ligação com o verbo. Payne (1997, p. 169) exemplifica essa noção com o verbo eat (comer, em inglês): tal verbo possui a valência de 2 , ou seja, envolve dois 'participantes', o comedor e a coisa a ser comida. Já a valência sintática, refere-se ao número de argumentos presentes na sentença. Mais uma vez, Payne (op. cit.) utiliza

\footnotetext{
Tal norma oficial de transliteração pode ser conferida no site da Organização Internacional de Padrões (ISO) http://www.iso.org/iso/home.html. As normas de transliteração para o japonês estão registradas sob o código ISO 3602:1989.
}

o exemplo do verbo eat e menciona que sintaticamente a valência para esse verbo pode ser de 1 ou 2, visto que existem sentenças em que o participante interpretado como o 'a coisa a ser comida' não é realizado na estrutura sintática (como objeto direto, por exemplo, se a oração estiver na voz ativa).

\section{Operações de Ajuste de Valência}

Todas as línguas possuem um ou mais tipos de sistema de operações que são responsáveis pelo 'ajuste' (no número) de papéis semânticos e as relações gramaticais. Para denominar esses sistemas, às vezes utiliza-se o termo 'voz' (voice) alternativa. No que se refere a papeis semânticos ou temáticos, Soares \& Menuzzi (2010, p. 14):

Os papéis temáticos, segundo os autores que os empregam, seriam as 'porções' dos significados dos verbos relevantes para a sintaxe. Eles representariam, de um lado, o modo como conceptualizamos o tipo de situação ou acontecimento do mundo expresso pelo verbo. Fariam isso codificando o modo como uma entidade - o argumento verbal - participa desta situação ou evento: um agente é um participante ativo, atuante; um paciente, é passivo e afetado, etc. Ao mesmo tempo, estes papéis seriam a informação que indicaria para a gramática da língua que mecanismos gramaticais - como posição na frase, concordância, preposições, etc - utilizar na expressão de um determinado argumento.

Basicamente, os sistemas consistem em operações morfossintáticas que ajustam a valência gramatical à oração (PAYNE, 1997, p. 170). Entre essas operações, temos as que produzem o aumento e o decréscimo (redução) de valência, como se pode observar no Quadro 1.

Entre as diversas operações expostas acima, tomaremos como foco deste trabalho as causativas. Nos capítulos a seguir, abordarei primeiramente a causatividade em seu sentido amplo, ou seja, uma definição mais padroni- 
zada sobre as causativas; posteriormente, após a apresentação da noção e dos tipos de causatividades que serão explorados, abordarei a causatividade voltada para a língua japonesa.

Quadro 1 - Operações de Ajuste de Valência

\begin{tabular}{|l|l|}
\hline \multicolumn{1}{|c|}{ Aumento } & \multicolumn{1}{c|}{ Decréscimo (redução) } \\
\hline Causativas & recíprocos \\
Aplicativos & passivas \\
Alteração de proeminência de argumentos & inversão (construções inversas) \\
Dativo de interesse & construções médias \\
Alçamento de possuidor ou possessão externa & antipassivas \\
& demoção de objeto e omissão \\
& incorporação de objeto \\
\hline
\end{tabular}

Fonte: A Autora.

\section{Causatividade}

Quando a causatividade envolve transitividade, temos as seguintes características: se o evento (a ser) causado for intransitivo, a causativa se torna transitiva; se o evento (a ser) causado for transitivo, a causativa será bitransitiva. Os elementos e os núcleos envolvidos em tal tipo de operação são dois:
(a) causee
(b) causer.

O causee nada mais é do que aquele que sofre a ação de causatividade, ou seja, é o 'causado'. Já o causer é o responsável por criar a situação causativa e também pode ser referido como o agente da causativa (PAYNE, 1997, p. 176).
Payne (op. cit.) menciona que as causativas podem ser divididas em três tipos:

(c) causativa lexical;

(d) causativa morfológica;

(e) causativa perifrástica/analítica.

Comrie (1989) organiza o mecanismo dos três tipos de causativa da mesma forma que Payne, porém, prefere chamar apenas de causativa analítica o que Payne considera como causativa perifrástica/analítica e apresenta dados breves que justificam cada tipo de causativa. Dixon (2012) também adota o conceito formulado por Comrie (op. cit.), porém, aprofundase mais sobre esse assunto. De acordo com Dixon (op. cit.), para identificar uma construção causativa, há diversos mecanismos. Tais mecanismos são: processos morfológicos, combinação de dois verbos em um predicado, meios perifrásticos. Por exemplo, temos o caso clássico do verbo leve 'make' do inglês, bem como o uso de auxiliares acompanhando o verbo principal (caso esse classificado como mais raro). Dentro do mecanismo chamado 'processos morfológicos', tem-se vários tipos, tais como:

(f) mudança interna (na vogal ou consoante);

(g) repetição de uma consoante;

(h) alongamento de vogal;

(i) mudança de tom;

(j) reduplicação ou vários processos de afixação com prefixo(s), sufixo(s), circunfixo(s) ou infixo(s).

Esses processos podem ser compreendidos a partir da tabela esquematizada por Dixon (op. cit.), com dados para exemplificar cada tipo de processo morfológico, a seguir: 
Quadro 2 - Processos Morfológicos para a marcação de causativas

\begin{tabular}{|c|c|c|c|c|}
\hline & Processo & Verbo Básico & Forma Causativa & Língua (fonte) \\
\hline (a) & mudança interna & $\begin{array}{c}\text { tikti } \\
\text { 'ser adequado' }\end{array}$ & $\begin{array}{c}\text { táiktyi } \\
\text { 'fazer adequado' }\end{array}$ & $\begin{array}{c}\text { Lituano } \\
\text { (Senn 1966:283) }\end{array}$ \\
\hline (b) & $\begin{array}{l}\text { repetição de } \\
\text { consoante }\end{array}$ & $\begin{array}{l}\text { xarab } \\
\text { 'ir mal' }\end{array}$ & $\begin{array}{c}\text { xarrab } \\
\text { 'fazer ir mal, ruína' }\end{array}$ & $\begin{array}{c}\text { Golfo Árabe } \\
\text { (Holes 1990:185) }\end{array}$ \\
\hline (c) & $\begin{array}{l}\text { alongamento de } \\
\text { vogal }\end{array}$ & $\begin{array}{l}\text { mar } \\
\text { 'morrer' }\end{array}$ & $\begin{array}{c}\text { ma:r } \\
\text { 'assassinar' }\end{array}$ & $\begin{array}{l}\text { Kashmiri } \\
\text { (Wali e Koul } \\
\text { 1997:211) }\end{array}$ \\
\hline (d) & mudança de tom & $\begin{array}{l}\text { n̄̄ (alta queda) } \\
\text { 'estar acordado' }\end{array}$ & $\begin{array}{l}\text { ñ̄ (nível baixo) } \\
\text { 'acordado, desperto' }\end{array}$ & $\begin{array}{c}\text { Lahu } \\
\text { (Matisoff 1973:33) }\end{array}$ \\
\hline (e) & reduplicação & $\begin{array}{l}\text { bengok } \\
\text { 'grito' }\end{array}$ & $\begin{array}{l}\text { be-bengok } \\
\text { 'fazer grito' }\end{array}$ & $\begin{array}{l}\text { Javanês } \\
\text { (Suhandano } \\
\text { 1994:64-5) }\end{array}$ \\
\hline (f) & prefixo & $\begin{array}{l}\text { gabba } \\
\text { 'entrar' }\end{array}$ & $\begin{array}{l}\text { a-gabba } \\
\text { 'inserir' }\end{array}$ & $\begin{array}{c}\text { Amárica } \\
\text { (Amberber 200:318) }\end{array}$ \\
\hline (g) & sufixo & $\begin{array}{c}\text { xaxhíi } \\
\text { 'estar se movendo' }\end{array}$ & $\begin{array}{c}\text { xaxhíi-a } \\
\text { 'movimento, em } \\
\text { movimento' }\end{array}$ & $\begin{array}{c}\text { Crow } \\
\text { (Graczyk 2007:141) }\end{array}$ \\
\hline (h) & circunfixo & $\begin{array}{l}\text { č́am- } \\
\text { 'comer' }\end{array}$ & $\begin{array}{c}\text { a- č 'am-ev- } \\
\text { 'alimentar } \\
\text { (fazer comer)' }\end{array}$ & $\begin{array}{c}\text { Georgiana } \\
\text { (Aronsom 1991:260) }\end{array}$ \\
\hline (j) & infixo & $\begin{array}{c}\text { buebae } \\
\text { 'perder o caminho' }\end{array}$ & $\begin{array}{c}\text { bue-da-bae } \\
\text { 'fazer perder } \\
\text { o caminho, } \\
\text { desencaminhar' }\end{array}$ & $\begin{array}{c}\text { Rabha } \\
\text { (Joseph 2005:83) }\end{array}$ \\
\hline
\end{tabular}

Fonte: Adaptado de Dixon (2012, p. 243)

Na subseção a seguir, veremos como os três tipos de causativas se comportam e como diferem.

\subsection{Causativas lexicais}

As causativas lexicais são as que possuem a ideia de causatividade intimamente ligada ao verbo. Payne (1997) afirma que as mesmas não são expressas por nenhum outro operador adicional. As causativas lexicais são divididas em três subtipos: (f) sem mudança no verbo;

(g) com mudança idiossincrática (sentido literal no verbo);

(h) com verbos distintos.

A distinção entre os três subtipos pode ser compreendida através do quadro comparativo, a ver:

Quadro 3 - Subtipos de Causativas Lexicais

\begin{tabular}{|l|c|c|c|}
\hline & Sem mudança & Causativas Lexicais & Mudança idiossincrática \\
Não causativa & The vase broke. & $\begin{array}{c}\text { The tree fell. } \\
\text { (verbo = "to fall") }\end{array}$ & $\begin{array}{c}\text { Stephanie ate beans. } \\
\text { Lucretia died. }\end{array}$ \\
\hline Causativa & $\begin{array}{c}\text { Mac Beth broke the vase. } \\
\text { (MacBeth caused the } \\
\text { vase to break) }\end{array}$ & $\begin{array}{c}\text { Bunyan felled the tree. } \\
\text { (verbo = to fell) }\end{array}$ & $\begin{array}{c}\text { Gedigan fed Stephanie } \\
\text { beans. } \\
\text { Gloucester killed } \\
\text { Lucretia. }\end{array}$ \\
\hline
\end{tabular}

Fonte: Adaptado de Payne (1997, p. 177).

É interessante ressaltar que ao contrário da divisão de Payne, Dixon (2012, p. 247) classifica as causativas lexicais em apenas duas:

(i) um lexema - pode ser utilizado tanto em uma função causativa quanto em uma não-causativa, sendo estritamente um verbo transitivo ou intransitivo. Tal fato pode ser compreendido a partir de dois exemplos utilizando-se o verbo 'hurt', do inglês: em My leg hurts, temos o caso de um verbo intransitivo, enquanto em John hurt my leg, a mesma forma passa à função causativa em vista do evento e dos argumentos envolvidos;

(j) dois lexemas - consistem em um par de lexemas distintos em que um pode ser o causativo do outro. No caso, um intransitivo, e, o outro, a causativa correspondente a esse (como, por exemplo, o verbo 'kill' que na realidade tem significado de 'make die'). 
Quanto aos critérios de ocorrência dos pares desse subtipo de causativa lexical, Dixon (2012) comenta que os critérios envolvidos são em sua grande maioria critérios semânticos, o que também é assumido por mim para dar conta de um subtipo de causativas no japonês, a ser abordado na subseção 4.3 Causativas-zero: causativas sem '-(s)ase.'

\subsection{Causativas morfológicas}

As causativas desse grupo possuem regras gramaticais em sua produção. Isso significa que a marca de causatividade será exibida através de morfema(s) causativo(s) afixado(s) à raiz do verbo. Em algumas línguas tal valor pode ser expresso por um ou mais morfemas, como no caso do turco que possui dois morfemas de causatividade: o morfema '-dIr' que é anexado a verbos intransitivos, enquanto ' $\mathrm{t}$ ' é utilizado em verbos transitivos. A exemplificação a seguir é de Payne (op. cit.)

(1) a. Hasan öl-dü Hasan die-PST

"Hasan died." (intransitive, non-causative)

b. Ali Hasan-t öl-dür-dü

Ali Hasan-ACC die-CAUS-PAST

"Ali killed Hassan." (causative of intransitive verb)

c. Müdür mektub-ü imzala-dt

director letter-ACC sign-PAST

"The director signed the letter." (transitive, non-causative)

d. Disçi mektub-ü müdür-e imzala-t-tl

dentist letter-ACC director-DAT sign-CAUS-PAST

"The dentist made the director sign the letter."

(PAYNE, 1997, p. 178)
Vale ressaltar que as causativas morfológicas, além de produzir o sentido de causatividade, também podem produzir o sentido de permissividade, como se pode observar na língua georgiana:

(2) Mama shvil-s ceril-s a-cer-ineb-s.

father son-DAT letter-ACC PREF-write-CAUS-3SG

"Father makes/ helps/ lets his son write the letter."

(PAYNE, 1997, p. 178)

\subsection{Causativas perifrásticas/ analíticas}

As causativas analíticas não envolvem mecanismos gramaticais para produzir uma causativa ou verbos que já possuem intrinsecamente a semântica de causatividade. Consistem na adição de um verbo causativo separadamente como, por exemplo, 'make' (fazer), 'cause' (causar) e 'force' (forçar), a seguir:

(3) a. He made me do it

b. Gloucester caused Lucretia to die

c. Melinda forced her hairdresser to relinquish his position

d. Marie compelled Taroo to dance with her.

(PAYNE, 1997, p. 181)

Ainda sobre esse tipo de causativa, Payne (1997) informa que embora as causativas possuam a interpretação semanticamente causativa, não são consideradas como operação de aumento de valência visto que basicamente consistem em um verbo que carrega a ideia de causa e o seu complemento é um evento causado². Segundo Comrie (op. cit.), as causativas analíticas são

${ }^{2}$ Nos casos de aumento de valência, podem ocorrer construções bitransitivas em que se figuram três argumentos: um argumento externo e dois argumentos internos como em: "A Joana deu um presente para Joan" e "Joana presenteou João". Esse tipo de aumento de valencia pode ser enquadrado como 
raras em termos de frequência e naturalidade, exibindo predicados distintos: um predicado indica a noção de causatividade enquanto o outro predicado indica o efeito dessa causatividade como em 'I caused John to go' ${ }^{3}$ (Eu causei/ fiz John ir).

\section{As causativas no japonês - 0 morfema causativo '-(s)ase'}

Harley (2006) afirma que as causativas no japonês têm grande importância na Linguística, haja vista as suas peculiaridades a serem abordadas brevemente durante as subseções deste artigo.

Para um nativo ou um aprendiz da língua japonesa, o sistema de aquisição de causativas pode não parecer complexo se levarmos em conta apenas o aspecto morfológico, ou seja, se apenas levarmos em conta as peças gramaticais e o mecanismo de formação do verbo causativo ou de uma sentença causativa. Porém, linguisticamente, há muitos fenômenos envolvidos tanto na formação quanto na aquisição e na leitura semântica.

Basicamente, o morfema que introduz a noção de causatividade é '-(s) ase'. Comumente, a consoante ' $\mathrm{s}$ ' é grafada entre parênteses, pois a ocorrência ou não variará de acordo com a característica de terminação do verbo, como se pode ver a seguir:

a) quando o verbo tem sua raiz terminada em vogal, temos '-sase' como seu sufixo:

$$
\begin{array}{lll}
\begin{array}{l}
\text { tabe } \\
\text { (comer) }
\end{array} & \rightarrow & \begin{array}{l}
\text { tabe-sase-ru } \\
\text { comer-CAUS-PRES }
\end{array} \\
\text { wasure } & & \text { wasure-sase-ru } \\
\text { (esquecer) } & \rightarrow & \begin{array}{l}
\text { esquecer-CAUS-PRES } \\
\text { mi }
\end{array} \\
\text { (ver) } & \rightarrow & \text { mi-sase-ru } \\
& & \text { ver-CAUS-PRES }
\end{array}
$$

\begin{tabular}{|c|c|c|}
\hline $\begin{array}{l}\text { nom } \\
\text { (beber) }\end{array}$ & $\rightarrow$ & $\begin{array}{l}\text { nom-ase-ru } \\
\text { beber-CAUS-PRES }\end{array}$ \\
\hline $\begin{array}{l}\text { aso } \underline{\mathbf{b}} \\
\text { (brincar) }\end{array}$ & $\rightarrow$ & $\begin{array}{l}\text { asob-ase-ru } \\
\text { brincar-CAUS-PRES }\end{array}$ \\
\hline $\begin{array}{l}\text { hanas } \\
\text { (falar) }\end{array}$ & $\rightarrow$ & $\begin{array}{l}\text { hanas-ase-ru } \\
\text { falar-CAUS-PRES }\end{array}$ \\
\hline
\end{tabular}

$\overline{3 \text { Comrie, op. cit., p. } 157 .}$ b) quando o verbo tem sua raiz terminada em consoante, teremos '-ase' como seu sufixo:

\begin{tabular}{|c|c|c|}
\hline $\begin{array}{l}\text { suru } \\
\text { (fazer) }\end{array}$ & $\rightarrow$ & $\begin{array}{l}\text { sase-ru } \\
C A U S-P R E S\end{array}$ \\
\hline $\begin{array}{l}\text { kuru } \\
\text { (vir) }\end{array}$ & $\rightarrow$ & $\begin{array}{l}\text { ko-sase-ru } \\
\text { vir-CAUS-PRES }\end{array}$ \\
\hline $\begin{array}{l}\mathrm{ka} \\
\text { (comprar) }\end{array}$ & $\rightarrow$ & $\begin{array}{l}\text { kaw-ase-ru } \\
\text { comprar-CAUS-PRES }\end{array}$ \\
\hline $\begin{array}{l}\text { su } \\
\text { (fumar) }\end{array}$ & $\rightarrow$ & $\begin{array}{l}\text { suw-ase-ru } \\
\text { fumar-CAUS-PRES }\end{array}$ \\
\hline $\begin{array}{l}\mathbf{i i} \\
\text { (dizer) }\end{array}$ & $\rightarrow$ & $\begin{array}{l}\text { iw-ase-ru } \\
\text { dizer-CAUS-PRES }\end{array}$ \\
\hline
\end{tabular}

De acordo com Harley (2006), a causativa no japonês é gerada a partir da adjunção do morfema '-(s)ase' ao radical do verbo, causando ou não alomorfia. É o caso dos verbos 'suru' (fazer) e 'kuru' (vir), tratados como irregulares e alguns verbos com raiz terminada em 'a', 'i' e ' $u$ ':

Ao observarmos o verbo 'suru' (fazer) e seu causativo, depreende-se que a origem do morfema '-(s)ase' está intrinsecamente ligada ao próprio verbo 'suru'. Harley (1995, p. 1) menciona de forma breve a origem de '-(s)ase': "Este morfema é o reflexo do verbo leve à frente que delimita a eventividade de um verbo, e é, portanto, denominado Evento P." 4

'This morpheme is the reflex of a light verb ahead which delimits the eventiveness of a verb, and is hence termed Event P' 
O verbo leve ao qual Harley se refere no trecho acima é justamente o verbo 'suru', que tem como equivalente no inglês o verbo ' $d o$ '. Sendo assim, a ideia de causatividade em que alguém faz/causa algo a outra pessoa ou coisa é confirmada pelo o que é dito pela autora em questão.

\section{Tipos de causativas}

Harley (1995) classifica as causativas em japonês em três grupos: causativas lexicais, causativas produtivas (possuindo dois tipos, porém, ambas portando a marca -(s)ase) e causativas-zero (em que não há a manifestação de -(s)ase), a serem abordadas nas subseções a seguir.

\subsection{Causativas lexicais}

As causativas lexicais são as que sofrem o fenômeno da idiomatização, ou seja, nos deparamos com o caso da idiossincrasia, em que a palavra deixa de ter o seu sentido canônico e passa a portar sentido distinto, a partir de algum fenômeno (não composicional) que ocorre ao longo dos tempos sendo que o sentido idiossincrático pode ser perdido ou, então, ficar 'camuflado'. Em português temos algumas idiomatizações como, por exemplo, 'pintar o sete' para a qual, até o presente momento, não há explicações referente à sua origem, apenas que seu significado atual é 'fazer bagunça'.

Retomando às causativas lexicais, temos como dados:

(4) Tarō-ga jishoku-o niow-ase-ta Taro-NOM própria demissão-ACC cheirar-CAUS-PST Taro deu sinal de sua demissão (Lit.: Taro'cheirou' a sua demissão)

(Adaptado de HARLEY, 2006, p. 3)
Tsujimura (1996, p. 260) afirma que as causativas lexicais '... são verbos transitivos que carregam sentido causativo que lhes é inerente" ${ }^{5}$. Por sua vez, Harley (1995, p. 1) vai além:

(...) a combinação $V$ + sase que os falantes de japonês tem uma forte intuição em algum senso forma uma 'palavra', e os argumentos de uma combinação lexical V+sase se comportam como membros de uma única oração. Nessas instâncias, a adição de -sase- ao verbo é comparável a uma alternação transitiva/incoativa tal como no inglês 'break' (quebrar) ou 'melt' (fundir). (...) 0 significado da combinação lexical V+sase é frequentemente idiossincrática, mais do que estritamente composicional $(. . .)^{6}$

Com isso, conclui-se que as causativas lexicais, por deixarem de apresentar uma leitura composicional, são consideradas expressões idiomatizadas na língua japonesa. Consequentemente, não são suscetíveis à produtividade, visto a sensação de 'lista' que o falante possui.

\subsection{Causativas produtivas}

Em relação às causativas produtivas, são divididas em dois tipos: causativas de 'fazer' (make causatives) e causativas de 'permissão' (let causatives):

(5) Hanako-wa Yoshi-o ik-ase-ta Hanako-TOP Yoshi-ACC ir-CAUS-PST Hanako fez Yoshi ir.

(6) Hanako-wa Yoshi-ni ik-ase-ta Hanako-TOP Yoshi-DAT ir-CAUS-PST Hanako fez ('permitiu', 'deixou') Yoshi ir.

(Tradução livre de HARLEY, 2006, p. 3)

5 "...are transitive verbs which bear causative meaning inherent to them" 6 "... a V+sase combination that speakers of Japanese have a strong intuition in some sense forms a "word", and the arguments of a lexical V+sase combination behave like members of a single clause. In these "break" or "melt" in English ( 
A diferença entre os dois tipos fica bem clara ao observarmos a contraposição dos dados: causativas produtivas de 'fazer', como o nome já diz, são aquelas em que o agente (causer ${ }^{7}$ ) faz ou provoca algo em relação ao paciente $\left(\right.$ cause $\left.^{8}\right)$, enquanto que as produtivas de permissão são as que introduzem o valor de permissão expresso entre o causer e o causee, ou seja, a ação de 'causar' é baseada em uma relação de permissão entre agente e paciente. Além disso, nas causativas produtivas de 'fazer', o causee recebe a marca de acusativo '-o' que indica paciente da ação causativa enquanto que nas causativas de 'permissão', o causee recebe a marca de dativo '-ni' (ver dados anteriores).

Porém, mesmo com tais marcas bem definidas, há um caso em que tanto a marca de dativo '-ni' quanto a marca de acusativo '-o' coexistem em sentenças como a que se segue:

(7) Haha-wa kodomo-ni miruku-o nom-ase-ta. mãe-TOP criança-DAT leite-ACC beber-CAUS-PST A mãe fez o filho beber o leite.

Tal situação ocorre quando nos deparamos com verbos transitivos, acarretando o fenômeno chamado double -o constraint ${ }^{9}$ : a fim de não ocorrerem duas marcas de acusativo em uma única sentença, o causee passa a carregar a marca de dativo, e o argumento interno ao verbo mantém a sua marca acusativa, o morfema '-o'. A diferença de '-ni' nas duas construções é que, na causativa de 'permissão', '-ni' é preposicional, enquanto que na causativa de 'fazer', é estrutural (visto o double -o constraint) ${ }^{10}$.

\footnotetext{
7 Payne (1997) e Harley (2006)

8 Payne (1997) e Harley (2006).

9 Restrição de duplo "-o".

${ }^{10}$ Ver, por exemplo, Harley, 2006.
}

Com exceção do caso (7) que indica o fenômeno do double -o constraint, a ideia de 'fazer' e de 'permissão' estaria restrita ao uso de '-o' e '-ni', como visto nos dados (5) e (6) respectivamente. Porém, o dado a seguir indica que é possível encontrar a noção de permissividade em sentenças que contêm a marca de acusativo:

(8) Haha-wa kodomo-ni piza o tabe-sase-ta. mãe-TOP criança-DAT pizza-ACC comer-CAUS-PST A mãe fez ('permitiu', 'deixou') o filho comer pizza.

O dado (8) exibe claramente a possibilidade de uma causativa de 'permissão' ocorrer juntamente com a marca de acusativo. Nocionalmente, nenhuma mãe obrigaria um filho a comer pizza; nesse caso, a melhor interpretação para esse dado seria de que a mãe permitiu, 'liberou' o filho para que fizesse esse tipo de refeição.

Ainda em relação às duas causativas produtivas, apesar de ambas possuírem certas peculiaridades, a questão de marcação não é o único fator que as diferencia: a configuração estrutural e suas 'leituras' também determinam suas particularidades ${ }^{11}$. Visto essa similaridade, Harley (1995) realizou testes para os dois tipos de causativas. Os testes tinham como objetivo identificar até que ponto as duas causativas seriam semelhantes. Para isso, Harley (1995) usou dados que envolviam causativa-passiva, modificação adverbial orientada para o agente ${ }^{12}$ e quantificadores. Os resultados podem ser observados no quadro resumitivo a seguir:

${ }^{11}$ Harley (1995) identifica que quando a causativa de fazer ('make causative') ocorre em verbos intransitivos, o argumento externo recebe a marca de caso acusativo ' $-o$ ', indicando que é o agente da passiva (causer). Já na causativa de permissão ('let causative'), o argumento externo recebe a marca de com o dativo '-ni' e o argumento interno com a marca de acusativo '-o'. Os dados (5), (6), (7) e (8) explicitam tais considerações respectivamente.

12 'agent-oriented' adverbs (HARLEY, 1995, p. 7) 
Quadro 4 - Resultados dos testes entre Causativas de 'fazer' e Causativas de 'permissão'

\begin{tabular}{|c|c|c|}
\hline & $\begin{array}{l}\text { Causativas de 'fazer' } \\
\text { (make causatives) }\end{array}$ & $\begin{array}{c}\text { Causativas de 'permissão' } \\
\text { (let causatives) }\end{array}$ \\
\hline $\begin{array}{l}\text { Ocorrem em construções de } \\
\text { causativa-passiva* }\end{array}$ & $\checkmark$ & $X$ \\
\hline $\begin{array}{l}\text { Permitem construções com } \\
\text { advérbios orientados } \\
\text { para o agente (causer)** } \\
\text { (agent oriented adverbs) }\end{array}$ & $\checkmark$ & $X$ \\
\hline 'oculta' quantificador flutuante*** & $\checkmark$ & $\mathrm{X}$ \\
\hline
\end{tabular}

* Pylkkänen (2000); Harley (2006).

** Harley $(1995 ; 2006)$.

*** Harley $(1995 ; 2006)$

Em relação à derivação, Harley (1995, p. 9) já apontava para diferenças em referência às projeções:

(9)

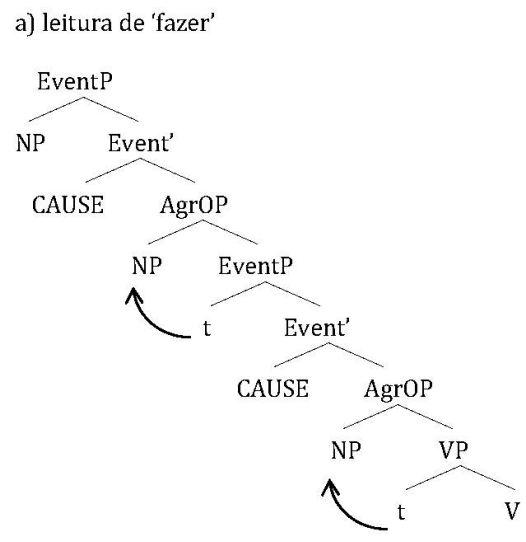

Fonte: Harley (1995, p. 9)

Harley (1995) confirma através de seus testes que, além das características abordadas no quadro resumitivo anterior, é na causativa de fazer que há um marcador de caso verdadeiro que permite quantificador flutuante. Entretanto, a causativa de permissão é preposicional e bloqueia o quantificador flutuante. $\mathrm{O}$ que Harley (op. cit.) buscou mostrar na derivação anterior é que, nas causativas de fazer, o argumento externo tem o seu caso atribuído diretamente pelo nó causativo, enquanto que na causativa de permissão, o argumento externo é marcado por uma preposição ('-ni') em uma frase preposicional introduzida pelo nó causativo. A frase preposicional controla um PRO na oração encaixada que é de fato o verdadeiro sujeito.

\subsection{Causativas-zero: causativas sem '-(s)ase'}

Harley afirma em seus artigos $(1995 ; 2005)$ que a ideia da causatividade no japonês não está apenas intimamente ligada à questão da composicionalidade ou da não composicionalidade do morfema '-(s)ase', visto que há outros verbos, mesmo sem tal morfema, que atribuiriam sentido de causatividade à estrutura da sentença. Tais verbos são chamados de causativas de marca zero. Basicamente, as causativas de marca zero não possuem '-(s)ase' em sua raiz, porém, também podem expressar a causatividade, como se pode observar:

(10) Tarō-wa fune-o shizume- ta Taro-TOP navio-ACC afundar -PST Taro afundou o navio (='fez' o navio afundar).

(Adaptado de HARLEY, 1995, p. 5)

Tal fato é explicitamente observado em verbos incoativos e inergativos (transitivos e intransitivos). Em japonês, essa nomenclatura pode se apresentar como jidōshi ${ }^{13}$ e tadōshi ${ }^{14}$, a serem abordados na próxima seção.

${ }^{13}$ Verbos intransitivos.

14 Verbos intransitivos. 


\subsubsection{Verbos transitivos versus verbos intransitivos no japonês}

O que torna o grupo dos verbos transitivos e intransitivos peculiarmente interessante é que muitas vezes, uma mesma raiz pode ser empregada nos dois contextos. Teramura (1982, p. 305) afirma que a divisão dos intransitivos se deu a partir da oposição entre as raízes dos verbos transitivos e intransitivos. A contraposição de raízes permitiu que tais tipos de verbos pudessem ser agrupados de acordo com suas características, a ver:

Quadro 5 - Composição dos grupos de verbos intransitivos e transitivos

\begin{tabular}{|c|c|c|c|c|}
\hline & $\begin{array}{l}\text { Morfema Funcional } \\
\text { Intransitivizador }\end{array}$ & $\begin{array}{l}\text { Morfema Funcional } \\
\text { Transitivizador }\end{array}$ & $\begin{array}{c}\text { Verbos } \\
\text { Intransitivos }\end{array}$ & $\begin{array}{c}\text { Verbos } \\
\text { Transitivos }\end{array}$ \\
\hline Grupo 1 & -ar- & $-\varnothing-$ & $\begin{array}{c}\text { fusag-ar-u } \\
\text { conectar, desligar }\end{array}$ & $\begin{array}{c}\text { fusag- } \emptyset-\mathrm{u} \\
\text { fechar, tapar, obstruir }\end{array}$ \\
\hline Grupo 2 & -ar- & -e- & $\begin{array}{c}\text { atar-u } \\
\text { bater, acertar }\end{array}$ & $\begin{array}{c}\text { at-e-ru } \\
\text { bater, acertar }\end{array}$ \\
\hline Grupo 3 & $-\varnothing-$ & -e- & $\begin{array}{l}\text { ak- } \varnothing-\mathrm{u} \\
\text { abrir }\end{array}$ & $\begin{array}{l}\text { ak-e-ru } \\
\text { abrir }\end{array}$ \\
\hline Grupo 4 & $-r-$ & $-s-$ & $\begin{array}{l}\text { mawa-r-u } \\
\text { girar }\end{array}$ & $\begin{array}{l}\text { mawa-s-u } \\
\text { girar }\end{array}$ \\
\hline Grupo 5 & -re- & $-\mathrm{s}-$ & $\begin{array}{l}\text { tao-re-ru } \\
\text { cair }\end{array}$ & $\begin{array}{l}\text { tao-s-u } \\
\text { derrubar }\end{array}$ \\
\hline Grupo 6 & -e- & -as- & $\begin{array}{c}\text { sam-e-ru } \\
\text { acordar, despertar }\end{array}$ & $\begin{array}{c}\text { sam-as-u } \\
\text { acordar, despertar }\end{array}$ \\
\hline Grupo 7 & $-\mathrm{i}-$ & -as- & $\begin{array}{l}\text { ik-i-ru } \\
\text { viver }\end{array}$ & $\begin{array}{l}\text { ik-as-u } \\
\text { manter vivo }\end{array}$ \\
\hline Grupo 8 & $-\mathrm{i}-$ & $-\mathrm{s}-$ & $\begin{array}{l}\text { och-i-ru } \\
\text { cair }\end{array}$ & $\begin{array}{l}\text { oto-s-u } \\
\text { derrubar }\end{array}$ \\
\hline Grupo 9 & $-\varnothing-$ & -se- & $\begin{array}{l}\text { mi-ø-ru } \\
\text { ver }\end{array}$ & $\begin{array}{l}\text { mi-se-ru } \\
\text { mostrar }\end{array}$ \\
\hline Grupo 10 & $-\varnothing-$ & -s- & $\begin{array}{l}\text { tob- } \varnothing-\mathrm{u} \\
\text { voar }\end{array}$ & $\begin{array}{l}\text { toba-s-u } \\
\text { pular, passar }\end{array}$ \\
\hline
\end{tabular}

Apesar da semelhança entre os verbos, nem sempre a semântica que carregam é necessariamente igual; nesses casos, o que vai definir a semelhança ou a diferença serão justamente os argumentos selecionados pelo verbo.

Teramura (op. cit.) discorre sobre cada grupo e sua especificidade, apontando as condições de uso e a morfologia interna do mesmo. Além disso, também menciona quais desses grupos são passíveis (ou não) de receber o morfema causativo '-( $s$ )ase', dando ênfase a partir do Grupo 4 até o Grupo 9, observando que é possível estabelecer uma relação entre as raízes desses grupos e a causatividade através do seguinte esquema:

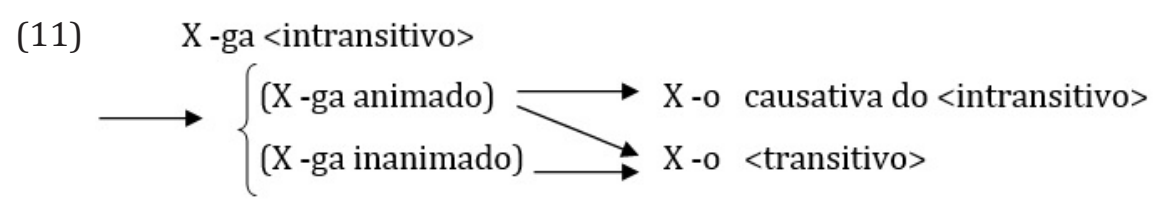

(Adaptado de TERAMURA, 1982, p. 313)

Os dados (5) e (6) listados na subseção 4.2 Causativas produtivas indicam o uso do morfema causativo '-(s)ase' com o verbo 'iku' (ir), que é um verbo intransitivo. Já nos dados (7) e (8) o morfema '-(s)ase' ocorre em verbos transitivos como 'nomu' (beber) e 'taberu' (comer), respectivamente.

É possível visualizar na subseção 4.3 que a ideia de causatividade não está apenas condicionada ao morfema '-(s)ase'; a noção de causatividade pode ser observada nos verbos transitivos (tadōshi) que possuem lexicalmente um par intransitivo (jidōshi).

O que Teramura (op. cit.) postula com o esquema (11) é que mesmo que o verbo transitivo dos pares lexicais não necessite de morfema causativo para atribuir sentido causativo, é possível que o verbo intransitivo possa também induzir a ideia de causatividade. Porém, esse por sua vez necessita da presença do morfema causativo '-(s)ase' adjungido à sua raiz, como se pode observar em (12): 
(12) a. Kodomo-ga ie-ni kae-r-u $\mathrm{u}^{15}$

criança -NOM casa-para retornar-TRANS-PRES

A criança retorna para casa.

b. Kodomo-o ie-ni kae-s-u

criança-ACC casa-para mandar/enviar de volta-TRANS-PRES

Mandar a criança de volta para casa.

c. Kodomo-o ie-ni kaer-ase-ru ${ }^{16}$

criança-ACC casa-para voltar-CAUS-PRES

Fazer a criança retornar para casa.

(Adaptado de TERAMURA, 1982, p. 313)

Tal como nos outros grupos, Teramura (op. cit.) apresenta em sua obra listas de verbos a fim de que as características compartilhadas entre os mesmos possam ser visualizadas com maior facilidade. Referentemente ao Grupo 9, a lista abaixo é de bastante relevância e gera algumas considerações:

Quadro 6 - Verbos intransitivos e transitivos referentes ao Grupo 9

\begin{tabular}{|cc|c|}
\hline <intransitivo & & $<$ transitivo \\
miru (trans.) & $\rightarrow$ & miseru \\
ver & & Mostrar \\
kiru (trans.) & $\rightarrow$ & kiseru \\
vestir & & vestir \\
abiru (intrans.? trans.?) & $\rightarrow$ & abiseru \\
banhar & & banhar, esguichar \\
niru (intrans.) & $\rightarrow$ & niseru \\
parecer, assemelhar & & imitar \\
noru (intrans.) & $\rightarrow$ & noseru \\
toma, pegar (meio de transporte) & & dar carona \\
\hline
\end{tabular}

Fonte: Adaptado de Teramura (1982, p. 316).

${ }^{15}$ No japonês, o morfema ' $-u$ ' pode codificar tanto tempo presente quanto forma infinitiva. Visto isso, as traduções podem variar entre a conjugação do presente do indicativo e a forma infinitiva sem que haja danos à interpretação dos dados presentes neste artigo.

16 Tal como o morfema '- $u$ ', o morfema '-ru' também codifica tempo presente e forma infinitiva.
A marca '-se-' expressa verbo transitivo, porém, nem todos os verbos da coluna da esquerda podem ser vistos só como intransitivos: os verbos 'miru' (ver) e 'kiru' (vestir) são tratados como transitivos (apesar de suas propriedades morfológicas) e possuem formas causativas - 'misaseru' e 'kisaseru', respectivamente. Por isso, os verbos 'miseru' e 'kiseru' na realidade são verbos que possuem características especiais que se assemelham aos causativos de verbos transitivos, portando, porém, certa especificidade semântica. A fim de justificar tal caso, são relacionados três dados:

(13) a. Tomodachi-ga suraido-o mi-ru amigo(a) -NOM slide-ACC ver-PRES $\mathrm{O}(\mathrm{A})$ amigo(a) vê um/o slide.

b. Tomodachi ni suraido-o mise-ru amigo(a) para slide -ACC mostrar-PRES Mostrar para o(a) amigo(a) um/o slide.

c. Tomodachi-ni suraido-o mi-sase-ru amigo(a) -DAT slide -ACC ver-CAUS-PRES Faço o(a) amigo(a) ver um/o slide.

(ação indireta)

(Adaptado de TERAMURA, 1982, p. 316)

Em relação aos verbos do Grupo 10, Teramura (1982) diz que alguns verbos intransitivos podem receber a marca causativa '-(s)ase', dependendo estritamente do traço [+animado]:

(14) a. Fuku-ga kawak-u roupa-NOM secar-PRES (verbo intransitivo) A roupa seca.

b. *Fuku-o kawak-ase-ru roupa-ACC secar-CAUS-PRES Fazer a roupa secar.

c. Fuku-o kawaka-s-u roupa-ACC secar-TRANS-PRES Secar a roupa. (causativa padrão)

(verbo transitivo)

(Adaptado de TERAMURA, 1982, p. 317) 
Já a forma '-as-' presente nos verbos transitivos é vista como uma forma reduzida da voz causativa.

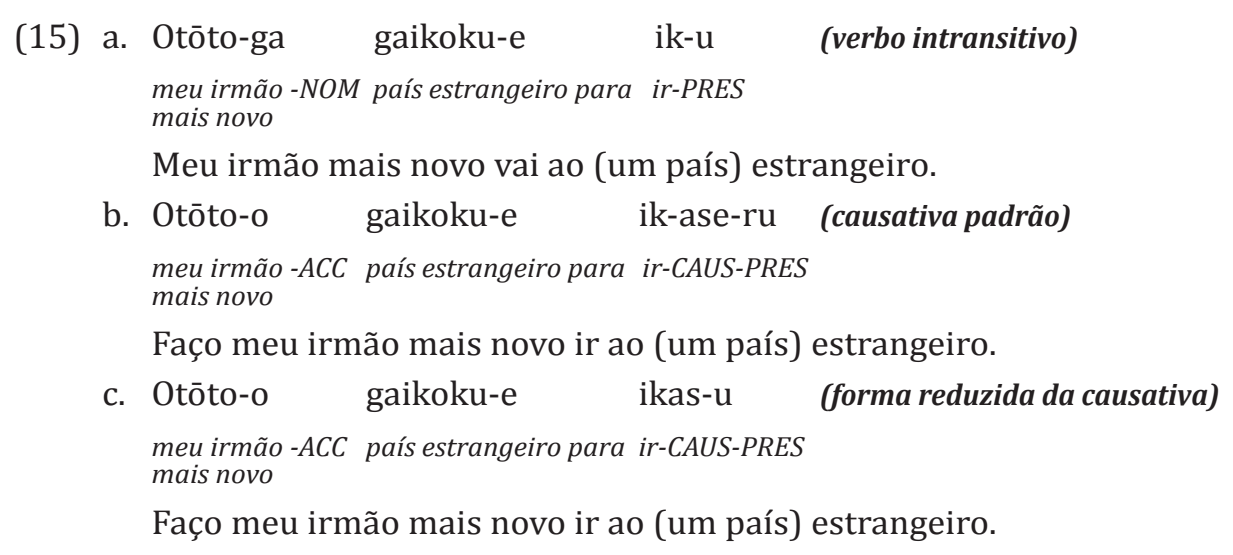

(Adaptado de TERAMURA, 1982, p. 317)

A partir dos dados levantados nesse capítulo, fica clara a linha tênue entre o grupo de verbos transitivos e intransitivos, a causatividade e o fenômeno blocking effect ${ }^{17}$ mencionado por Harley (2006) em face ao questionamento sobre a produção de causativas lexicais, sintáticas e causativas de marca zero.

\section{Verbos causativos idiomatizados}

Como abordado anteriormente, as causativas lexicais são verbos já 'pré-fabricados', porém, com certa mudança em seu significado. Foram detectados alguns verbos que ocorrem juntamente com o morfema '-(s)ase', porém, não configurando expressão idiomática:

\footnotetext{
${ }^{17} \mathrm{O}$ blocking effect é um fenômeno em que os morfemas bloqueiam uns aos outros a partir das necessidades sintáticas até que um seja selecionado.
}
(16) a. Te-o awase-ru
mãos-ACC juntar-PRES
Juntar as mãos.

b. Seikatsuyōshiki-o atarashii kankyō-ni awase-ru estilo de vida -ACC novo(a) ambiente para adaptar-PRES Adaptar-se o estilo de vida ao novo ambiente.

c. Tenisu shiai-de kare-to kumiawase ni natta Tênis jogo-LOC ele com combinar foi decidido (Foi decido) que combinaria (=faria par) com ele no jogo de tênis.

\section{(Dicionário Sūpā daijirin)}

Em contrapartida, a formação da raiz com o causativo e a ocorrência com determinados nomes permite uma leitura idiomática:

(17) a. Chikara-o aw-ase-

força-ACC junto-CAUS

Reunir.

b. Mimi-o sum-ase- 18 orelha-ACC limpo, claro-CAUS

Escutar atentamente/ cuidadosamente.

(Adaptado de HARLEY, 2006, p. 17)

\section{Causativas adversativas}

No capítulo dedicado às causativas, Payne (1997) coordena uma pequena discussão sobre os dois tipos de integração que as causativas possuem em relação ao sentido de causa e efeito: integração estrutural e integração

${ }^{18}$ Sumase(ru) é equivalente ao verbo suma(su), cuja característica remonta ao Grupo 10 , citado na seção anterior 
conceitual. Como o próprio nome já sugere, a integração estrutural tem referência à forma, à estrutura; já a integração conceitual tem relação com o tipo de causatividade a ser expresso: se é direta ou indireta.

Basicamente, a causativa direta é aquela em que o efeito é gerado diretamente. Payne (1997) exemplifica a diferença entre o que é um efeito direto e indireto através do verbo 'kill' e 'die': 'kill' é uma causativa lexical que expressa o efeito causativo direto, enquanto que 'die' é uma causativa analítica, de efeito indireto, visto que a morte foi causada, mas não de forma direta.

Pylkkänen (2000) considera que no japonês, há dois tipos de construções adversativas: adversativas passivas e adversativas causativas. Como o presente trabalho objetiva uma síntese referente às causativas, nos ateremos nesse momento apenas às adversativas causativas.

De acordo com Pylkkänen (2000), o sentido da adversatividade é gerado visto que a sentença se torna ambígua entre a 'verdadeira' interpretação causativa e a interpretação adversativa (que seria o que Payne classifica como causativa indireta), a ver:

(18) Tarō-wa kaisha-o tōsan-sase-ta Taro-TOP empresa-ACC falir-CAUS-PST

(i) Taro levou a empresa à falência;

(ii) Taro foi afetado pela falência da empresa; (ou seja: Taro faliu a empresa e isso o afetou de alguma forma)

(Adaptado de MIYAGAWA, 1989, p. 129 e HARLEY, 2006, p. 17)

(19) Tarō-ga musuko-o shin-ase-ta. Taro-NOM filho -ACC morrer-CAUS-PST

(i) Taro causou a morte do filho;

(ii) Taro foi afetado pela morte do filho (visto a perda);

(Adaptado de PYLKKÄNEN, 2000, p. 7)
De acordo com Pylkkänen (2000), para que haja uma causativa adversativa é necessária uma relação possessiva entre o argumento externo e o argumento interno para que ocorra o efeito adversativo, de 'ser atingido'. Os dados em (18) e (19) refletem tal relação entre seres de traço [- animado] e [+ animado], que seriam 'kaisha' (empresa) e 'musuko' (filho), respectivamente.

Ao olharmos o dado (19), a primeira interpretação que teríamos provavelmente seria de que Taro tivesse feito o filho cometer suicídio, porém, a 'primeira impressão' é equivocada. A leitura das duas interpretações se dá de forma que Taro causa a morte do filho de forma indireta ou não tão indireta:

(i) forma indireta: Taro faz algo que inesperadamente e sem saber (sem ter culpa) causa a morte de seu filho;

(ii) forma não tão indireta: Taro faz algo que acaba contribuindo para a causa da morte de seu filho;

Harley (2006) argumenta que a partir da interpretação das causativas adversativas há como distinguir a causativa lexical da sintática, como sugerem os dados a seguir:

(20) a. Boku-wa kodomo-o gake kara otoshi-ta eu-TOP criança-ACC despenhadeiro FON deixarcair-PST

(i) Eu derrubei a criança do despenhadeiro.

(ii) Deixei a criança cair e fui afetado (por isso).

b. Boku-wa kodomo-o gake kara ochi-sase-ta eu-TOP criança-ACC despenhadeiro FON cair-CAUS-PST (i) Eu causei, fiz a criança cair do despenhadeiro.

*(ii) A criança caiu do depenhadeiro e eu fui afetado. (Produtiva)

(Adaptado de HARLEY, 2006, p. 33)

A partir do que foi visto em relação à ideia de causatividade direta/ indireta, confirmam-se as três considerações tecidas por Payne (1997) 
concernentes à relação entre a integração estrutural e conceitual, chamadas pela autora de 'princípios de codificação das causativas':

1. Distância Estrutural: o número de sílabas ou segmentos envolvidos na operação causativa é iconicamente relacionado à quantidade de distância conceitual entre a causa e o efeito. (HAIMAN, 1983a).

2. Formas verbais finitas versus formas verbais não-finitas: se a causa e o efeito são os mesmos em termos de tempo/aspecto/modalidade/evidencialidade e/ou localização, um dos verbos pode ser não-finito (por exemplo, não marcado para tempo/aspecto, etc.)

3. Caso morfológico do causee: se o causee retém um alto grau de controle sobre o evento causado, o mesmo aparecerá em um caso normalmente associado com AGENTES, por exemplo, o caso nominativo ou ergativo. Se retiver pouco ou nenhum controle (por exemplo, é completamente manipulado pelo causer), aparecerá em um caso normalmente associado com pacientes, por exemplo, caso acusativo ou absolutivo (PAYNE, 1997, p. 182$)^{19}$.

\section{Conclusões}

Buscou-se apresentar através deste trabalho um breve levantamento das formas causativas existentes nas línguas naturais utilizando Payne (1997) para posteriormente compará-las com as três formas de causativas, ou seja, identificar os padrões linguísticos existentes na língua japonesa - causativas lexicais, causativas produtivas e causativas zero - com base nos dados de Harley (1995; 2006) e Teramura (1982). Em relação à marcação de caso,

19"1. Structural distance: the number of syllables, or segments, involved in the causative operation is iconically related to the amount of conceptual distance between the cause and the effect (Haiman 1983a).

2. Finite vs non-finite verb forms: if cause and effect are the same in terms of tense/aspect/modality/ evidentiality and/or location, one of the verbs can be non-finite (i.e., not marked for tense/aspect, etc). 3. Morphological case of the causee: if the causee retains a high degree of control over the caused event it .Morphological case of the causee: if the causee retains a high degree of control over the caused event it witl appear associated with patients, e. con the accusative or absolutive case"
Payne (op. cit.) afirma que a relação estabelecida para a marcação de caso nominativo e acusativo é a relação entre o alto e o pouco ou nenhum grau de controle do causee sobre o evento causado. Harley (op. cit.) corrobora a proposta de Payne (op. cit.) quando indica que se a causativa de 'fazer' ocorrer com verbo intransitivo, o argumento interno recebe a marca de acusativo '-o', indicando o causee. Já na causativa de 'permissão', o causee recebe a marca de dativo '-ni' independente dos verbos envolvidos serem transitivos ou intransitivos. Porém, para Harley (op. cit.), mais do que a marcação de caso, a configuração estrutural e suas interpretações são também relevantes, culminando com a projeção proposta pela autora e representada em (9), na subseção 4.2 Causativas produtivas.

A abordagem aqui proposta visou dirimir os questionamentos sobre o assunto e abrir novos horizontes para mais pesquisas no campo da causatividade e seus efeitos como, por exemplo, as causativas adversativas abordadas por Pylkkänen (2000), as causativas-zero - grupo de verbos transitivos que podem portar o sentido de causatividade mesmo sem carregar o traço gramatical -(s)ase e também no que tange às idiomatizações. Sabe-se que a idiomatização pode incidir em qualquer nível da estrutura sintática de uma palavra complexa. Porém, há idiomatizações que requerem um contexto que inclua o argumento interno. Visto isso, é necessário identificar e delimitar qual/quais é/são o(s) tipo(s) de contexto(s) sintáticos em que tal fenômeno ocorre.

\section{Referências}

COMRIE, Bernard. Language universals and linguistic typology. 2. ed. Chicago: University of Chicago, 1989. http://dx.doi.org/10.2307/413584

DIXON, Robert Malcolm Ward. Causatives. In: Basic Linguistic Theory: Further Grammatical Topics, v. 3. New York: Oxford University, 2012, p. 239-249. http://dx.doi.org/0.1075/ sl.38.4.11hau 
HARLEY, Heidi. Little v: History, function and analysis. In: Morfologia Distribuída. ABRALIN, Março, 2003. Disponível em: <http://dingo.sbs.arizona.edu/ hharley/ courses/ABRALIN/Lecture4Littlev.pdf>. Acesso em: 19 mar. 2009.

On the causative Construction. 2006. Disponível em: <http://babel.ucsc.edu/ hank/ mrg.readings/harley_06_On-the-causativ.pdf>. Acesso em: 19 mar. 2009. http://dx.doi. org/10.1093/oxfordhb/9780195307344.013.0002

Sase Bizarre: The Structure of Japanese Causatives. Cambridge: MIT, 1995. Disponível em: <http://dingo.sbs.arizona.edu/ hharley/PDFs/HarleySaseCLA1996. pdf>. Acesso em: 6 abr. 2009.

KUNO, Susumu. The Structure of Japanese Language. In: Current Studies in linguistics series Volume 3. Cambridge: MIT, 1981.

MATSUMURA, Akira. Sūpā daijirin jiten. [s.l.]: Sanseido, 2006.

SOARES, Eduardo Correa; MENUZZI, Sérgio de Moura. Introduzindo e problematizando papéis temáticos e hierarquias temáticas. Signo (UNISC Online), v. 35, p. 13-43, 2010. http://dx.doi.org/10.17058/signo.v35i59.1432

MURASUGI, Keiko; HASHIMOTO, Tomoko; KATO, Sachiko. On the Acquisition of Causatives in Japanese. In: Online Proceedings Supplement of BUCLD 28. 2004. Disponível em: http:// www.bu.edu/bucld/files/2011/05/28-Murasugi.pdf Acesso em 31 jul. 2009. http:// dx.doi.org/10.1515/LING.2007.019

NARAHARA, Tomiko. The Japanese Copula: forms and functions. Hampshire: Palgrave Macmillan, 2002. http://dx.doi.org/10.1057/9780230504530

PAYNE, T. Voice and valence adjusting operations. In: Describing Morphosyntax: a guide for field linguists. Cambridge: Cambridge University Press, 1997, p. 169-222.

PYLKKÄNEN, Liina. What Applicative Heads Apply To. In: Proceedings of the $24^{\text {th }}$ Annual Penn Linguistics Colloquium. U. Penn Working Papers in Linguistics, v. 6.4, Article 18, 2000, p. 197 -210. Disponível em: <http://web.mit.edu/norvin/www/24.956/Pylkkanen.pdf>. Acesso em 5 mar. 2009. http://dx.doi.org/10.1.1.413.2405

TERAMURA, Hideo. Dōshi no Jita - Goitekitai no ruikei (Transitividade e Intransitividade dos verbos: tipos similares do estado lexical). In: Nihongo no Shintakusu to imi. Tóquio: Kuroshio, v. 1, 1982, p. 303-317.

TSUJIMURA, Natsuko. An Introduction to Japanese Linguistics. Blackwell textbooks in linguistics, v. 10. Cambridge: Cambridge University Press, 1996.

\section{ANEXO I}

\section{Abreviaç̃̃es e convenções}

\begin{tabular}{|l|l|}
\hline ACC & acusativo \\
CAUS & causativo \\
DAT & dativo \\
FON & fonte \\
NOM & nominativo \\
PRES & presente \\
PST & passado \\
TOP & tópico \\
TRANS & transitivizador \\
\hline
\end{tabular}

Recebido em 05/04/2015. Aceito em 13/08/2015. 